\title{
A importância das bibliotecas escolares para o desenvolvimento de práticas de leitura
}

\author{
The importance of school libraries for the development of reading practices \\ La importancia de las bibliotecas escolares para el desarrollo de las práctivas de lectura
}

Recebido: 31/12/2021 | Revisado: 05/01/2022 | Aceito: 08/01/2022 | Publicado: 12/01/2022

\author{
Elaine Silva Santos \\ ORCID: https://orcid.org/0000-0002-3058-5412 \\ Secretaria de Estado de Educação, Brasil \\ E-mail: elainesilvasantos15@hotmail.com \\ Mayara Rossi \\ ORCID: https://orcid.org/0000-0002-9182-1888 \\ Instituto Federal de Mato Grosso, Brasil \\ E-mail: professoramayararossi@hotmail.com \\ Estêveno de Freitas Rodrigues \\ ORCID: https://orcid.org/0000-0002-0031-3619 \\ Instituto Federal de Mato Grosso, Brasil \\ E-mail: estevenorodrigues@hotmail.com \\ Lilian Regina Simões \\ ORCID: https://orcid.org/0000-0002-7609-1813 \\ Secretaria de Estado de Educação, Brasil \\ E-mail: lilian.simoes@unemat.br \\ Vanusa Maria de Oliveira \\ ORCID: https://orcid.org/0000-0001-8901-3374 \\ Instituto Federal de Mato Grosso, Brasil \\ E-mail: vanusa.oliveira_@hotmail.com \\ Paula Daniella Leão Braun \\ ORCID: https://orcid.org/0000-0002-2442-3257 \\ Secretaria de Educação do Estado do Mato Grosso, Brasil \\ E-mail: paulabraun_nx@hotmail.com \\ Nilvana Gomes da Silva \\ ORCID: https://orcid.org/0000-0002-6577-1717 \\ Secretaria de Estado de Educação, Brasil \\ E-mail: nilvana_gomes@hotmail.com \\ Juliana Aparecida Reis Marcelino \\ ORCID: https://orcid.org/0000-0001-6795-9425 \\ Secretaria de Estado de Educação, Brasil \\ E-mail:marcelinoju2@gmail.com \\ Roseane da Silva Rodrigues \\ ORCID: https://orcid.org/0000-0003-1062-897X \\ Secretaria de Estado de Educação, Brasil \\ E-mail: roseanedasilvarodrigues2@gmail.com \\ Sônia Aparecida Araújo Verdelho \\ ORCID: https://orcid.org/0000-0003-1584-6423 \\ Secretaria de Estado de Educação, Brasil \\ E-mail: soniaverdelho@hotmail.com
}

\begin{abstract}
Resumo
Este trabalho reflete sobre a importância das bibliotecas para o desenvolvimento de práticas de leitura, cujo objetivo é identificar como estão sendo utilizadas as bibliotecas escolares para o incentivo da leitura em duas escolas estaduais do Mato Grosso, descrevendo e relatando como este espaço escolar pode contribuir (ou não) para com a formação de um leitor. Pretende-se descrever como a biblioteca está atuando em condições de estrutura física, acervo e recursos humanos e como estes fatores podem influenciar a formação de leitor. Primeiramente realizamos uma pesquisa bibliográfica para entendermos melhor a trajetória da biblioteca e suas modificações ao longo do tempo, com a análise percebeu-se que a biblioteca veio se transformando de acordo com homem, antigamente somente para a guarda, atualmente para disseminar o conhecimento. Posteriormente, realizamos uma pesquisa de campo para entendermos melhor a influência desse ambiente e como está sendo utilizado para fortalecer o hábito de leitura. Como conclusão da pesquisa, verificamos que é indiscutível a importância da biblioteca na formação do cidadão leitor, esse ambiente é um recurso didático fundamental para incentivar o hábito de leitura, através de atividades de leitura como histórias, contos ou músicas e outras. Por isso, é necessário que as escolas deem atenção para as bibliotecas, programando e planejando projetos, pois são raras as escolas onde professores e bibliotecários estão envolvidos nessas práticas. A biblioteca possui um valor inestimável, dado que pode enriquecer o intelecto do ser humano, transformando-o em um sujeito crítico e reflexivo, capaz de transformar a sociedade, se o local for usado com sabedoria.
\end{abstract}

Palavras-chave: Biblioteca; Práticas de leitura; Cidadão-leitor. 


\begin{abstract}
This work reflects on the importance of libraries for the development of reading practices, whose objective is to identify how school libraries are being used to encourage reading in two state schools in Mato Grosso, describing and reporting how this school space can contribute (or not) towards the formation of a reader. It is intended to describe how the library is acting in conditions of physical structure, collection and human resources and how these factors can influence reader formation. First, we carried out a bibliographic research to better understand the history of the library and its changes over time, with the analysis it was noticed that the library has been transformed according to man, formerly only for the guard, currently to disseminate knowledge. Later, we carried out field research to better understand the influence of this environment and how it is being used to strengthen the reading habit. As a conclusion of the research, we verified that the importance of the library in the formation of the citizen reader is indisputable, this environment is a fundamental didactic resource to encourage the reading habit, through reading activities such as stories, stories or songs and others. Therefore, it is necessary that schools pay attention to libraries, programming and planning projects, as schools where teachers and librarians are involved in these practices are rare. The library has an inestimable value, as it can enrich the human being's intellect, transforming him into a critical and reflective subject, capable of transforming society, if the place is used wisely.
\end{abstract}

Keywords: Library; Reading practices; Citizen-reader.

\title{
Resumen
}

Este trabajo sobre la importancia de las bibliotecas para el desarrollo de las prácticas lectoras, cuyo objetivo es identificar cómo se están utilizando las escuelas para fomentar la lectura en dos escuelas públicas de Mato Grosso) hacia la formación del lector. Se pretende describir cómo está actuando la biblioteca en condiciones de estructura física, colección y recursos humanos y cómo los factores pueden influir en la formación de lectores. En primer lugar, realizamos una búsqueda bibliográfica para comprender mejor la historia de la biblioteca y sus cambios a lo largo del tiempo, con el análisis se notó que la biblioteca se ha transformado según un hombre, antes solo para la guardia, actualmente para difundir conocimientos. Posteriormente, realizamos una investigación de campo para comprender mejor la influencia de este entorno y cómo se está utilizando para fortalecer el hábito lector. Como conclusión de la investigación, comprobamos que la importancia de la biblioteca en la formación del ciudadano lector es indiscutible, este entorno es un recurso didáctico fundamental para fomentar el hábito lector, a través de actividades lectoras como cuentos, cuentos o canciones y otros. Por lo tanto, es necesario que las escuelas presten atención a las bibliotecas, los proyectos de programación y planificación, las escuelas donde maestros y bibliotecarios están involucrados en estas prácticas son raras. La biblioteca tiene un valor inestimable, ya que puede enriquecer el intelecto del ser humano, transformándolo en un sujeto crítico y reflexivo, capaz de transformar la sociedad, si se utiliza con sabiduría el lugar.

Palabras clave: Biblioteca; Prácticas de lectura; Ciudadano-lector.

\section{Introdução}

A leitura é uma prática muito importante em nossas vidas, dado que, por meio dela podemos ter acesso a diversos conhecimentos. Ela se faz presente desde o nascimento de um ser humano, o que podemos chamar de leitura de mundo, pois pequenos gestos e sons estão por toda a parte, onde há uma interpretação pessoal de cada pessoa. A leitura pode nos transformar em indivíduos melhores, conscientes, críticos, reflexivos, capazes de transformar o mundo com nossas ações.

A leitura deve fazer parte do dia a dia das pessoas, principalmente nos lares, tendo contato com diferentes tipos de textos como jornais, revistas, livros, histórias, etc. Os pais ou responsáveis devem incentivar seus filhos na mais tenra idade para a leitura, inicialmente contando histórias, lendo com eles ou para eles, para que assim possam desenvolver o gosto pela leitura e futuramente se tornarem leitores habituais.

No entanto, em muitos lares e até mesmo em escolas, espaço onde deveria se priorizar essa prática, a leitura não faz parte da vida de muitos alunos, nas salas de aula os professores não instigam os mesmos a lerem de uma forma atraente. Ressaltamos que a biblioteca, uma fonte de conhecimento essencial para a escola representa um "recurso indispensável para o desenvolvimento do processo ensino-aprendizado e formação do educando" (Garcia, 1989, p. 11). Sem esse espaço educativosocial; a escola torna-se "uma instituição incompleta, e uma biblioteca não orientada para um trabalho escolar dinâmico tornase um instrumento estático e improdutivo" (Garcia, 1989, p.11).

A biblioteca escolar deve ser vista como um dos ambientes mais importantes do espaço escolar porque "é a porta de entrada para o conhecimento, fornece as condições básicas para o aprendizado permanente, autonomia das decisões e para o 
desenvolvimento cultural dos indivíduos e dos grupos sociais" (Manifesto da UNESCO apud PimenteL, Bernardes \& Santana, 2007, p. 25).

Mesmo sabendo de sua importância, as bibliotecas, na maioria das vezes, não passam "de verdadeiros depósitos de livros ou, o que é pior, de objetos de natureza variada, que não estão sendo empregados no momento, seja por estarem danificados, seja por terem perdido sua utilidade" (Silva, 1999, p. 15). Assim, o que vem ocorrendo com frequência, é que esse ambiente não está sendo utilizado como recurso disseminador do conhecimento.

A escola deve ser um local de aprendizado e de transformação, mas para isso acontecer é preciso que os professores modifiquem seus métodos e suas práticas tornando-as atrativas para os alunos, para que fortaleçam o hábito de ler. A escola em conjunto com professores e bibliotecários deve articular métodos a fim de que o desenvolvimento de práticas de leitura atrativas e dinâmicas seja algo praticado constantemente junto aos alunos, seja na sala de aula, na biblioteca ou fora da escola.

Desse modo, sabendo-se da importância da leitura e a da biblioteca escolar é lançado o seguinte questionamento: De que forma as bibliotecas podem ser utilizadas como ambientes para o desenvolvimento de atividades de leitura, considerandose questões como a estrutura física, os recursos humanos, o acervo e os serviços por elas oferecidos?

A fim de que possamos responder a essa indagação faz-se necessário primeiramente um estudo sobre a origem da biblioteca, suas funções e seu histórico, analisando suas transformações ao longo do tempo e sua evolução histórica.

A biblioteca ao longo do tempo sofreu mudanças, passando da função de armazenamento para a de guardiã, atualmente sua função vai além de um local de guarda e preservação, um espaço que pode auxiliar o desenvolvimento do processo de ensino e aprendizagem e o desenvolvimento intelectual do leitor. Contudo, para isso acontecer, é necessário que ela se constitua como um local favorável e agradável, onde professores e bibliotecários estejam compromissados para proporcionar aos alunos atividades e práticas de leitura diferenciadas e que esse ambiente faça parte do mundo real do aluno.

Por isso, desenvolvemos o presente trabalho com o objetivo principal de identificar, conhecer e relacionar a importância das bibliotecas escolares para o desenvolvimento de práticas de leitura em duas escolas estaduais da rede de ensino público de Cacoal/RO; atentando-se para a realidade das bibliotecas no que se refere ao ambiente, acervo e práticas de leituras ofertadas.

Portanto, esta pesquisa se justifica pela necessidade de, em conjunto com a escola, refletirmos sobre a presença e da utilização de bibliotecas escolas; bem como pela oportunidade de ampliação de nossas formas de conhecimento e de relacionamento com a comunidade em que a universidade se encontra inserida.

A concretização do trabalho se deu por meio da pesquisa bibliográfica e de campo. A bibliográfica procurou entender a importância da biblioteca, sua origem e funções, e como esse ambiente pode contribuir, ou não, para com desenvolvimento de práticas de leitura. A pesquisa de campo se deu por meio de identificação e observação das bibliotecas, analisando a estrutura física, acervo e os recursos humanos oferecidos, assim como pela verificação da existência, ou não, de projetos de leitura.

Este trabalho encontra-se organizado estruturalmente em quatro partes, com exceção da introdução: fundamentação teórica, metodologia, resultados e discussão e considerações finais. Na fundamentação teórica (primeira parte) aborda-se a origem da biblioteca, suas funções antepassadas e atuais e seu histórico, ainda trazemos sobre a importância da biblioteca e das práticas de leitura para formação de leitores habituais.

A segunda parte descreve o método utilizado neste trabalho, assim como a pesquisa de campo realizada e os instrumentos utilizados para sua concretização. Os resultados obtidos encontram-se na terceira parte e foram dispostos em tabelas com detalhamento da coleta de dados e na descrição das observações efetuadas. Nesse tópico ainda trazemos uma síntese dos resultados e discussões acerca do mesmo a respeito da pesquisa realizada. Por fim, como parte final tecemos 
algumas considerações ressaltando a relevância da biblioteca na formação do aluno-leitor e como ambiente de vivências e de saberes sócio-culturalmente construídos.

\section{Metodologia}

Para elaboração deste trabalho utilizamos o método qualitativo. Para Minayo (2003, p. 22) este método "não se preocupa com representividade numérica, mas aprofunda-se no mundo dos significados das ações e relações humanas, um lado não perceptível e não captável em equações, médias e estatísticas".

Os procedimentos adotados nesta investigação foram a pesquisa bibliográfica e a pesquisa de campo, respectivamente.

Segundo Lakatos e Marconi (2003), a pesquisa bibliográfica é o levantamento de toda a bibliografia já publicada seja em forma de livros, revistas, publicações digitais ou impressas, escritas ou em áudios e vídeos, sendo considerada como o primeiro passo de toda pesquisa científica a ser realizada.

De acordo com Fachin (2003), a pesquisa de campo ocorre a partir da observação de um fato em um contexto social, identifica-se um problema que passa a ser investigado; estabelecido os métodos e técnicas específicos dá-se as explicações do fato, ou seja, o problema.

Nesse sentido, iniciamos este trabalho com pesquisas e leituras acerca do histórico da biblioteca, elaborando a fundamentação teórica necessária à construção da historicidade do objeto. Posteriormente, ampliamos o estudo com uma pesquisa de campo, efetiva pela observação dos ambientes utilizados como bibliotecas em duas escolas da rede estadual do ensino fundamental de Cacoal/ RO.

Com a observação e análise realizadas nas escolas foi possível a elaboração de tabelas para melhor visualização das realidades focalizadas; optamos pela utilização das tabelas, pois essa forma de disposição de informações:

[...] facilita, ao leitor, a compreensão e interpretação rápida da massa de dados, podendo apenas com uma olhada, apreender importantes detalhes e relações. Todavia seu propósito mais importante é ajudar o investigador na distinção de diferenças, semelhanças e relações, por meio da clareza e destaque que a distribuição lógica e a apresentação gráfica oferecem às classificações (Lakatos \& Marconi, 2003, p. 169).

Após a análise das tabelas propomos uma visão geral das bibliotecas escolares, abordando diversos aspectos para podermos estruturar uma visão mais ampla desses ambientes.

O universo de desenvolvimento do trabalho constituiu-se de duas escolas públicas no município de Cacoal/ R, doravante identificadas como escola A e escola B.

Ambas são escolas da periferia da cidade de Cacoal, atendem a uma clientela formada basicamente por filhos de trabalhadores autônomos ou de prestadores de serviços que exercem atividades braçais, diaristas e ajudantes de construção, cujos rendimentos oscilam entre 01 a 03 salários mínimos. Os sujeitos participantes foram os bibliotecários que atuam nas duas escolas.

\section{Fundamentação Teórica}

\subsection{Bibliotecas: origens, funções e histórico}

A história da escrita e da impressão de livros acompanham a história da biblioteca. Um grande avanço da humanidade ocorreu quando da invenção da escrita e com esta a necessidade de criar um local específico para a conservação deste material responsável pela memória de uma determinada sociedade.

Desse modo, a biblioteca surgiu como guardiã de saberes e conhecimentos historicamente construídos por um determinado grupo humano. 
De acordo com Ferreira (1986) a palavra biblioteca significa:

subst. Fem. 1. Coleção pública ou privada de livros e documentos congêneres, organizada para estudo, leitura e consulta. 2. Edifício ou recinto onde se instala essa coleção. 3. Estante ou outro móvel onde se guardam e/ou ordenam os livros (Ferreira, 1986, p. 253).

Em sua evolução histórica há relatos de que a biblioteca mais antiga existiu há cerca de três mil anos antes da era cristã, egípcios e assírios guardavam papiros e tábulas de argila, como uma forma encontrada por eles para preservar o conhecimento adquirido evitando assim que ele se perdesse (Britânnica do Brasil, 1997).

De acordo com Britânnica do Brasil (1997) e também Pimentel, Bernardes e Santana (2007) na antiguidade a biblioteca não era conhecida como disseminadora de conhecimento. O conceito nesta época era apenas o de conservação, servindo somente como depósito. Uma das primeiras bibliotecas, desta época, foi construída pelo rei Assurbanipal, último rei da Assíria que chegou a reunir aproximadamente cerca de vinte cinco mil tábuas de argilas organizadas e catalogadas de acordo com o assunto, além de ser uma das primeiras a existir foi a primeira a ter uma organização padronizada.

Outra biblioteca da antiguidade que continha uma grande coleção era a de Pérgamo, construída por Átalo I, localizada na Ásia menor. Nela, o rei chegou a reunir cerca de duzentos mil volumes.

$\mathrm{Na}$ Grécia, Pisístrato fundou uma biblioteca com conceito diferenciado. Embora nessa época as bibliotecas fossem apenas para guardar as obras e não fossem abertas para visitação, a de Pisístrato era pública e tinha como objetivo reunir obras de autores famosos daquele tempo (Britânnica do Brasil, 1997).

Em Roma, o conceito de biblioteca era como guardiã de coleções, que se deu a partir de duas origens distintas: as bibliotecas particulares e as públicas. As bibliotecas particulares tinham o acervo constituído por obras obtidas por meio de saques de guerras compondo até o fim do período republicano de Roma, 27 a.C. um significativo número (Santos, 2012).

Segundo Santos (2012), Júlio Cézar foi o responsável pela ideia de criar bibliotecas públicas em Roma, sendo a primeira construída no forúm romano, na qual continha dois locais para leitura de obras em latim e grego. No século IV, o imperador Trajano fundou a maior biblioteca do mundo chamada de Ulpiana, além de muitas outras, totalizando vinte oito bibliotecas. Mesmo com toda a importância, incêndios e caos políticos destruíram a maioria das bibliotecas públicas romanas.

A biblioteca de Alexandria foi, talvez, a mais conhecida e valorizada da antiguidade. Localizava-se no Egito, fundada na dinastia ptolomaica por Ptolomeu I, a maior e principal se localizava no Bruquíon nos palácios reais. Demétrio de Falera, um filósofo muito importante da época, conseguiu convencer Ptolomeu I a construir a estrutura e a buscar obras e mais obras para a coleção que posteriormente seria ainda mais ampliada por Ptolomeu II e Ptolomeu III.

Além da vasta coleção do acervo, a biblioteca de Alexandria era uma das mais organizadas da época, pois as obras eram identificadas por etiquetas que continham o nome do autor e o título. Seus bibliotecários, filósofos e humanistas tornaram-se detentores de grande poder. Vários incêndios terminaram por destruir totalmente a rica e variada coleção. Já na Idade Média, existiram três tipos de bibliotecas: as monacais, as bizantinas e as universitárias. As monacais eram espaços que ficavam dentro dos mosteiros e conventos mantidas por monges que copiavam e guardavam as obras em locais secretos com receio de roubo. As Bizantinas analogamente a anterior era mantida por monges, só que eram núcleos de civilização helênica, com conteúdo considerado profano para os cristãos. As universitárias surgiram já no fim da Idade Média, no começo do Renascimento com o papel de disseminar o conhecimento (Santos, 2012).

Com a invenção da impressão por tipos móveis, de Johann Gutenberg, o livro começou a ganhar mais força com o intuito de tornar a leitura algo atraente, a palavra escrita começou ter mais foco com a reprodução ampliada, ocorreu então o barateamento do livro, enquanto alguns países passavam a explorar a impressão a fim de atrair mais leitores.

No Brasil, durante o período colonial, a família real proibiu qualquer tipo de reprodução impressa, com receio de 
propagação de ideias de independência por parte dos colonos. Os primeiros livros que chegaram ao Brasil foram os trazidos pelos jesuítas no século XVI, com objetivo de possibilitar a catequização dos índios e a instrução formal dos filhos daqueles que formavam as elites da época.

Posteriormente, nas palavras de Válio (1990) pouco a pouco os acervos foram aumentando e tornaram-se de uso particular dos Jesuítas, não havendo no país nenhum outro tipo de biblioteca ou livraria, que promovesse a formação de leitores, pois ninguém mais se interessava em lê-los, uma que mais de $80 \%$ da população era constituída por analfabetos (inclusive o próprio colonizador).

Porém, com a expulsão dos jesuítas, os livros das bibliotecas foram usados para embalar ou embrulhar mercadorias e o restante dos exemplares terminou por estragar em depósitos de péssima qualidade.

Com a vinda de D. João VI para o Brasil, em 1808, parte do acervo da Biblioteca Real foi trazido, uma vez que a existência desse espaço representava mais que um hábito de ler, mas uma forma de ilustração de poder. A respeito dessa questão, é preciso notar que, [...] se, por um lado as bibliotecas fortaleciam a imagem de poder e erudição dos governantes, por outro, também demonstravam, ao longo da história sua enorme fragilidade diante de guerras, incêndios, saques e súbitas catástrofes naturais (El Far, 2006, p.17).

Com o intuito de divulgar legislação e papéis diplomáticos a serviço da casa real, foi criada a Impressão Régia que, com o tempo, sem ter mais o que imprimir e como era crescente a demanda de livros, o governo passou a imprimir algumas obras, especialmente para a leitura, mas antes de imprimi-las eram fiscalizadas, assim como também, fiscalizavam-se as obras que saiam e entravam no país.

Segundo El Far (2006), em 1827 foram criadas as primeiras escolas e, com elas, deu início ao processo civilizatório do país, que demandava a discussão pela criação de bibliotecas escolares a partir da fundação do Conselho de Instrução do Império por meio da análise das características nacionais e de métodos de leitura.

Os primeiros títulos a serem publicados em terras brasileiras eram voltados para as crianças. Com o tempo as bibliotecas foram observando a importância da leitura e reservando espaço não somente para adultos, mas também valorizando obras voltadas para o público infantil (Válio, 1990).

A função da biblioteca inicialmente era mais "[...] voltada mais para a preservação do acervo do que para sua disseminação" (Pimentel et al., 2007, p. 19). As funções de guardiã, locais de recolha e armazenamento de documento era um de seus principais aspectos; em parte sua função era proteger e guardar ou, até mesmo, esconder as obras, já que, por vezes, “[...] tinham por objetivo a intenção de impedir a saída do acervo” (Santos, 2012, p. 176).

Assim, as bibliotecas "[...] eram vistas como espaços para intelectuais. [...] privilégios de poucos" (Pimentel et al., 2007, p. 19). O Acesso a elas era estritamente restrito, destinadas apenas àqueles que detinham alguma forma de poder.

Hoje o conceito de biblioteca é outro, para além de guarda e preservação, organiza os conteúdos de forma acessível e livre, fornece um espaço agradável para a leitura, apoio ao professor. Houve mudanças também nas funções do bibliotecário, em que este agora ajuda o leitor a escolher determinado livro e pode auxiliar o desenvolvimento do processo de ensino/aprendizagem e as capacidades intelectuais do leitor.

Embora, com o tempo, os conceitos acerca das bibliotecas tenham mudado, sua importância e função de disseminadora e guardiã continuam ainda altamente presente em nossa sociedade.

\subsection{A biblioteca como espaço de leitura}

A leitura começa a fazer parte da nossa vida desde cedo, passamos a compreender o mundo ao nosso redor assim que abrimos nossos olhos pela primeira vez (Freire, 2003). Esta primeira leitura é anterior ao processo de aquisição do código verbal escrito e se caracteriza principalmente pela leitura de imagens, sensações, gestos ou modos. 
A partir da aquisição da escrita, passamos a outra forma de leitura: a da palavra; que "[...] não se esgota na decodificação pura da palavra escrita ou da linguagem escrita, mas que se antecipa e se alonga na inteligência do mundo" (Freire, 2003, p. 13).

Desse modo, conforme Martins (2003, p. 23) o ato de ler pode ser entendido como uma forma de "inteirar-se do mundo, sendo também uma forma de conquistar a autonomia, de deixar ler pelos olhos de outrem".

Sua prática pode nos transformar em seres mais capazes de opinar, optar, decidir e analisar problemas, porque pode possibilitar crescimento intelectual, preparando os indivíduos para viver na sociedade atual.

Mas para isso, deve ser um ato diário, pois assim cria-se uma intimidade com o mundo das palavras, que por sua vez pode facilitar o processo de escolarização formal, pois como afirma Martins (2003, p. 25) o hábito da leitura enquanto pequeno pode ser "a ponte para o processo educacional eficiente, proporcionando a formação integral do indivíduo".

Por isso, faz-se necessário que os pais, desde cedo, insiram seus filhos no mundo da leitura, lendo para eles histórias infantis e incentivando-os a ler. Este contato pode o incentivar para que ele crie o próprio hábito de ler. Assim ao criar um vínculo com os livros, revistas, jornais, etc. se concretiza a utilização da linguagem escrita. Além disso, é preciso observar que “[...] na formação do leitor é imprescindível que haja, a princípio, pessoas envolvidas a meios/recursos para o desenvolvimento de gosto e competência para a leitura" a fim de que ela configura-se como atividade essencial da vida em sociedade (Bicheri \& Júnior, 2013, p. 41.

Nesse sentido, a biblioteca apresenta-se como elemento fundamental para a formação do leitor, pois representa um ambiente em que todos podem ampliar sua visão de mundo, já que esse espaço pode possibilitar muitos benefícios as pessoas, como:

- ampliar conhecimentos, visto ser uma fonte cultural;

- colocar à disposição dos alunos um ambiente que favoreça a formação e desenvolvimento de hábitos de leitura e pesquisa;

- oferecer aos professores o material necessário à implementação de seus trabalhos e ao enriquecimento de seus currículos escolares;

- colaborar no processo educativo do ensino-aprendizado, dentro dos princípios exigidos pela moderna pedagogia;

- proporcionar aos professores e alunos condições de constante atualização de conhecimentos, em todas as áreas do saber (Garcia, 1989, p. 12).

Contudo, deve-se observar o fato de que apenas a existência da biblioteca, por si só, não constitui as reais possibilidades de formação de um leitor. Faz-se necessário que o professor exerça o papel de agente mediador no processo educacional e venha despertar o interesse dos estudantes pela leitura, tendo a biblioteca como grande aliada; haja vista que ela pode possibilitar o acesso a diferenciados e diversificados suportes que podem proporcionar ao leitor fruição, enriquecimento do vocabulário e ampliação das possibilidades de atribuir e entender significados.

Portanto, é preciso atentar para Becker e Grosch (2008, p. 36), quando, ao se referirem à questão da relação entre formação do leitor e bibliotecas afirmam que elas:

[...] assumem papel fundamental ao possibilitar às pessoas o acesso à leitura, através do seu acervo e, mais precisamente, por meio daqueles que são a mais fiel tradução do conhecimento disponibilizado no mundo: os livros. Tamanha é a responsabilidade daqueles que a administram, pois pequenas ações dentro das bibliotecas podem constituir-se em eventos significativos na promoção da leitura (Becker \& Grosch, 2008, p. 36).

Por outro lado, Bicheri e Júnior (2013, p. 43) colocam que para a biblioteca venha a cumprir seu papel é preciso, "além de espaço e acervo, de um bibliotecário competente e engajado na escola como um todo". Além disso, afirmam os autores anteriores que o bibliotecário "se envolva com a comunidade escolar, tenha sabedoria e goste de trabalhar com 
crianças, adolescentes e adultos

Ainda diante de tamanha importância dada a leitura e as bibliotecas a maioria das instituições de ensino não se utiliza desse recurso para o desenvolvimento de tais práticas. Frequentemente, a escola, e muitos professores veem a biblioteca escolar apenas como "lugar em que são armazenados livros de leitura: um lugar destinado a alunos considerados indisciplinados" (Garcia, 1989, p. 13).

Não só os professores devem se preocupar com a formação dos alunos, mas “[...] também os profissionais bibliotecários têm que estar atentos para as novas necessidades de leitura e formação do leitor de nossos alunos, diversificando ações que promovam o prazer de ler e a formação do leitor” (Becker \& Grosch, 2008, p. 43).

O problema que se corporifica é como desenvolver atividades atraentes em prol da formação do leitor se os professores apenas trabalham com os livros didáticos, e não utilizam a biblioteca para essas atividades, nem estimulam o aluno. que promovam o prazer de ler e a formação do leitor” (Becker \& Grosch, 2008, p. 43).

O problema que se corporifica é como desenvolver atividades atraentes em prol da formação do leitor se os professores apenas trabalham com os livros didáticos, e não utilizam a biblioteca para essas atividades, nem estimulam o aluno.

Frente a essa questão, Garcia $(1989$, p.90) ressalta que:

Para conquistar leitores nem sempre bastará oferecer acesso aos livros. No cotidiano do aluno de escola pública o livro é elemento desconhecido ou pouco presente, com exceção do livro didático. Sem alguma estimulação, sem uma apresentação à biblioteca, será difícil que o aluno venha a freqüenta - lá ou a interessar-se por leituras.

Além disso, Becker e Grosch (2008) esclarecem que:

Embora a escola devesse ser o local responsável em promover ações que desenvolvam o prazer de ler, indo ao encontro de práticas do letramento, as práticas em nossas escolas nem sempre contribuem para formar cidadãos leitores. E as bibliotecas, que deveriam ser o cérebro das instituições escolares, funcionam (quando existem), como apêndice da educação: sem bibliotecário, localizadas em salas impróprias, com acervo desatualizado e sem diversidade de leituras (escrita, virtual, etc), sem atividades que promovam o prazer de ler, etc. (Becker \& Grosch, 2008, p. 40).

As crianças devem se preparar para que, futuramente, estejam capacitadas a lidar com a informação e a resolver problemas diversos. Para tanto, é preciso que as escolas ofereçam profissionais, tanto professores quanto bibliotecários preparados e competentes para desenvolver e ensinar as crianças a buscarem o conhecimento e a lidar com diversas situações com as quais nos deparamos no dia a dia.

As bibliotecas em conjunto com a escola e professores devem preparar as crianças para o futuro, oferecer e incentivar práticas de leituras a fim de que elas possam ter a convicção que a leitura é um ato que pode mudar seu rumo neste mundo.

A biblioteca deve oferecer um espaço atraente e confortável para o leitor, e seu acervo estar atualizado e diversificado, sempre buscando atrair as crianças e os jovens para o mundo da leitura, como forma de inseri-las, democrática e eticamente na sociedade.

\section{Resultados e Discussão}

Os dados referentes às condições de atendimento encontram-se dispostos na Tabela 1 abaixo: 
Tabela 1 - Formação e horário de atendimento.

\begin{tabular}{l|c|c}
\multicolumn{1}{c|}{ ITEM } & ESCOLA A & ESCOLA B \\
\hline NÚMERO DE FUNCIONÁRIOS & 02 & 02 \\
\hline FUNCIONÁRIOS COM FORMAÇÃO EM & 00 & 00 \\
BIBLIOTECONOMIA & & Letras e Letras \\
\hline FORMAÇÃO ATUAL & Magistério e Pedagogia & Consulta e empréstimo; \\
\hline SERVIÇOS OFERECIDOS & Consulta e empréstimo; & Pesquisas; \\
& Pesquisas; Acesso à internet. & $07: 30-11: 30$ \\
\hline HÓRARIO DE ATENDIMENTO & & $07: 30-11: 30$ \\
& $13: 30-17: 30$ & $13: 30-17: 30$ \\
\hline
\end{tabular}

Fonte: Dados coletados pelos autores na pesquisa (2015).

A Tabela 1 mostra que os funcionários responsáveis pelas bibliotecas dessas escolas não possuem curso superior em biblioteconomia, embora seja fundamental a existência de pelo menos um funcionário com essa formação específica, pois esses apresentam competências e habilidades para catalogação, conservação e organização do material disponível para leitura.

Os funcionários entrevistados que ocupam estes cargos nas bibliotecas estão entre os chamados de "desvio de função" isto ocorre na maioria das bibliotecas públicas, os responsáveis ocupam essa função por não estarem mais aptos para a docência em sala de aula.

Silva (1999) esclarece esta situação quando caracteriza tais profissionais como:

professores que, por doença, velhice ou fastio pedagógico, são "encostados" nas bibliotecas das escolas, visto que este é, no espaço escolar, o melhor lugar para o repouso profissional, até que chegue a aposentadoria ou outra oportunidade de trabalho (Silva, 1999, p. 16).

Com isso, as bibliotecas não se tornam atraentes aos leitores, uma vez que poucos dos atuais profissionais que nesse ambiente se encontram estão desmotivados ou desinteressados devido a estarem nessa função apenas de passagem ou cumprindo um papel que não é o seu e para o qual não tiveram a devida formação universitária ou técnica.

Sobre a estrutura e instalações a Tabela 2 mostra as dimensões das bibliotecas analisadas. Por meio da tabulação dos dados podemos ter uma noção melhor sobre o espaço oferecido e das condições atuais do ambiente e de suas acomodações.

Tabela 2 - Dimensões e condições físicas.

\begin{tabular}{c|c|c}
\hline ITEM & ESCOLA A $^{\mathbf{1}}$ & ESCOLA B $^{\mathbf{2}}$ \\
\hline TAMANHO DA BIBLIOTECA & $5 \mathrm{~m} \mathrm{X} \mathrm{5m}$ & $13 \mathrm{~m} \mathrm{X} \mathrm{8} \mathrm{m}$ \\
\hline CONDIÇÕES DA ESTRUTURA FÍSICA & Medianas & Boas \\
\hline $\mathbf{N}^{\circ}$ DE MESAS & 04 & 08 \\
\hline $\mathbf{N}^{\circ}$ DE CADEIRAS & 12 & 30 \\
\hline
\end{tabular}

Fonte: Dados coletados pelos autores na pesquisa (2015).

Informações importantes a respeito do tamanho da biblioteca, das condições da estrutura física oferecida e da sua capacidade de acomodação de alunos são aspectos importantes para o desenvolvimento de atividades de leitura e para a realização de pesquisas e trabalhos neste ambiente, e para isso acontecer de forma produtiva é imprescindível um ambiente agradável, climatizado e com espaço.

A escola A apresenta um pequeno espaço disponível. De acordo com as informações fornecidas não foi projetado para tal fim. A biblioteca passou a ser neste local por falta de outro local apropriado, com isso o espaço no qual se constitui a

\footnotetext{
${ }^{1}$ A escola A atende a um total de 418 alunos regularmente matriculados no Ensino Fundamental.

${ }^{2}$ A escola B atende a uma clientela de 776 alunos, divididos entre o Ensino Fundamental e o Médio.
} 
biblioteca é pequeno e não é capaz de acomodar muitos alunos, ocasionando problemas se professores com salas superiores a 12 alunos forem fazer pesquisas na biblioteca, afetando futuros trabalhos ou pesquisas e prejudicando os alunos por não oferecem boas condições estruturais. Já a escola B, embora com instalações fora do padrão necessário, apresenta uma estrutura física e capacidade melhores que as da escola A, dado que suas dimensões possibilitam um número maior de mesas e de cadeiras, ou seja, possibilita maior acomodação de alunos.

Outro ponto crucial para utilização das bibliotecas está relacionado as instalações físicas presentes nesses ambientes, isso pode ser verificado na Tabela 3 a seguir:

Tabela 3 - Instalações físicas.

\begin{tabular}{c|c|c}
\hline ITEM & ESCOLA A & ESCOLA B \\
\hline $\mathbf{N}^{\circ}$ DE LÂMPADAS & 03 & 12 \\
\hline $\mathbf{N}^{\circ}$ DE VENTILADORES & 01 & 00 \\
\hline $\mathbf{N}^{\circ}$ DE CONDICIONADORES DE AR & 01 & 02 \\
\hline $\mathbf{N}^{\circ}$ DE COMPUTADORES & 00 & 02 \\
\hline
\end{tabular}

Fonte: Dados coletados pelos autores na pesquisa (2015).

A Tabela 3 mostra a quantidade de recursos materiais, a escola A possui uma pequena quantidade de lâmpadas, pois seu espaço é menor, está em local inapropriado, não é de fácil acesso, possui apenas duas janelas, tornando o espaço sem a ventilação adequada e pouco arejada, o que pode prejudicar não só os alunos, quanto à saúde, mas também a acervo no que diz respeito à sua conservação.

A esse respeito, Garcia (1989) diz que o espaço de uma biblioteca deve corresponder a:

Uma sala com tamanho suficiente para acomodar o acervo e uma classe de alunos é o espaço mínimo recomendado. Se possível, num local silencioso, longe da quadra de esportes e pátio de recreio. Ventilação, iluminação adequada e ausência de umidade são cuidados a serem observados, para que se crie um ambiente agradável para os leitores e adequado à conservação dos livros (Garcia, 1989, p. 37).

Já a escola B, apresenta um espaço maior e planejado, com janelas amplas e portas adequadas, com arejamento melhor e fácil acesso, facilitando assim, futuras pesquisas, leituras ou trabalhos a serem realizados.

Outro fator de grande importância para o aproveitamento das bibliotecas como ambiente favoráveis ao desenvolvimento de atividades de leitura refere-se à questão da organização com que são disponibilidades os elementos constituintes de seu acervo. É o que podemos observar pelas informações coletadas na seguinte tabela:

Tabela 4 - Organização e constituição do acervo.

\begin{tabular}{c|c|c}
\hline ITEM & ESCOLA A & ESCOLA B \\
\hline POR DISCIPLINA & $10 \%$ & $15 \%$ \\
\hline POR AUTOR & $15 \%$ & $20 \%$ \\
\hline POR GÊNERO & $75 \%$ & $65 \%$ \\
\hline ACERVO & ABERTO & FECHADO \\
\hline
\end{tabular}

Fonte: Dados coletados pelos autores na pesquisa (2015). 
A Tabela 4 mostra o critério de organização do acervo, percebe-se que as duas escolas organizam seu acervo pelo gênero. A escola A deixa o acervo em aberto pelo pequeno espaço disponível, o aluno tem a liberdade de escolher e pegar sozinho o livro que desejar.

A escola B limita o acesso ao público, deixando apenas o livre acesso aos servidores responsáveis pela biblioteca, com o espaço aberto o leitor poderia ter uma proximidade maior com os livros. Essa questão é fundamental quando a biblioteca atende principalmente o público infantil, já que "[...] para que as crianças leiam regularmente, é necessário que tenham a oportunidade de acesso ao livro" criando assim uma intimidade e quem sabe um possível hábito" (Válio, 1990, p. 20). Nesse intento, o atendimento preferencialmente voltado para o público infantil e a constituição do acervo configura-se como elementos importantes dentre vários outros.

Tabela 5 - Constituição do acervo.

\begin{tabular}{c|c|c}
\hline ITEM & ESCOLA A & ESCOLA B \\
\hline LIVROS & $97 \%$ & $96 \%$ \\
\hline REVISTAS & $1 \%$ & $2 \%$ \\
\hline GIBIS & $1 \%$ & $1 \%$ \\
\hline JORNAIS & 0 & 0 \\
\hline OUTROS & $1 \%$ & $1 \%$ \\
\hline
\end{tabular}

Fonte: Dados coletados pelos autores na pesquisa (2015).

A Tabela 5 mostra a realidade da maioria das escolas públicas, onde boa parte do acervo é constituída por livros, que em sua maioria, não são obras de literatura, tais como romances, livros de contos, poesias ou crônicas. Grande parte desses acervos é constituída por livros didáticos em desuso ou semidestruídos e que se encontram empilhados em fileiras, sem um destino correto, esperando professores utilizarem ou apenas empoeirar.

Analisando os dados referentes às bibliotecas das duas escolas pode-se verificar que nenhum dos ambientes pesquisados possui um profissional capacitado na área de biblioteconomia.

Comparativamente a escola B possui um local melhor e mais apropriado, com mais acomodações, uma estrutura física em boas condições, fácil acesso, ambiente agradável se comparado a escola $\mathbf{A}$.

Diante da pesquisa constatamos que na escola B já foram desenvolvidos projetos voltados para práticas de leitura; mas segundo os funcionários que atuam na biblioteca esses projetos eram trabalhos de professores e não propriamente focalizados na leitura. Atualmente, a biblioteca não está envolvida em nenhum projeto de leitura, de acordo dados disponibilizados os professores da escola não comparecem com frequência à biblioteca.

Silva (1999) explica bem essa situação quando afirma que:

Não são poucos os casos de professores que jamais entraram nas bibliotecas das escolas em que lecionam ou que já têm pronto um argumento para explicar a distância que mantêm da biblioteca escolar. Os mais comuns são: "ela não tem recursos", "está desatualizada", "está sempre fechada". [...] Mas é aí que se coloca o problema: até quando os professores vão permanecer alegando que a biblioteca não tem condições de ser utilizada? (Silva, 1999, pp 19-20).

Contudo, faz-se necessário observar que, embora a escola B destaque-se em relação aos itens anteriormente colocados, a escola A possui um diferencial: a responsável pela biblioteca realiza um trabalho de grande valor juntamente com a escola, um projeto que visa incentivar o hábito da leitura.

$\mathrm{O}$ referido projeto funciona da seguinte maneira: os alunos vão à biblioteca e podem escolher livremente um livro de acordo com seu gosto. Ao terminar de ler, o aluno conta a história para a responsável da biblioteca, que analisa sua 
interpretação e anota em uma tabela o nome do aluno, seu ano escolar e sua turma, dependendo do livro e a sua interpretação em relação ao livro, o aluno acumula pontos e, ao final do mês, em um mural localizado na biblioteca, o leitor do mês tem uma fotografia sua exposta.

A observação das fichas de retirada de obras e as tabelas de controle da biblioteca dessa escola permitiram identificar uma significativa participação dos alunos para os quais, no final do ano, há uma eleição do leitor mais assíduo, com entrega de prêmio.

Ainda que essa seja uma ação simples é de grande valia, pois é capaz de atrair os estudantes para o mundo da leitura, tornando a biblioteca escolar um ambiente mais socializado e mais presente na vida escolar dos alunos.

\section{Considerações Finais}

A leitura é essencial na vida de todo ser humano, ela pode desenvolver a escrita, tornar o indivíduo mais crítico e reflexivo, capaz de pensar e agir de uma forma mais consciente e participativa na sociedade atual. Todavia, para que isso aconteça, essa prática deve ser valorizada como atividade fundamental dentro do ambiente escolar, como também fora dele.

Precisa-se considerar comumente a importância da biblioteca escolar para o desenvolvimento do hábito de leitura, por ser um local que pode propiciar a ampliação do conhecimento.

As práticas de leitura são essenciais em uma escola. O ideal é que todos os profissionais da educação compreendam a relevância que a biblioteca possui no âmbito escolar e possam contribuir para que essas práticas de leitura possam realmente acontecer.

Realizamos uma pesquisa bibliográfica, primeiramente, para entender aspectos relacionados a biblioteca e a sua importância, como já mencionado, seguida da pesquisa de campo para verificarmos a realidade atual das bibliotecas escolares, a fim de que pudéssemos entender e verificar como estão sendo realizadas as práticas de leitura, e como a biblioteca contribui para com a formação de possíveis leitores habituais.

De modo geral, podemos concluir que, nas duas escolas onde foram feitas as observações há falta de profissionais formados na área para atuarem na biblioteca. Bem como, os professores não a visitam regularmente, necessidade de melhor organização e planejamento a fim de que a biblioteca realmente constitua-se como ambiente propício à formação do leitor.

Verificamos que há a necessidade da existência de, pelo menos, um profissional com formação específica, técnica ou universitária, para atuar na biblioteca escolar. Sendo fundamental tornar o ambiente da biblioteca um espaço de produção de conhecimento e de cultura. Bem como, imprescindível o desenvolvimento de projetos diversos e que possam contemplar as diferentes áreas do conhecimento com as quais as crianças tenham contato no início do processo de escolarização e durante ele.

Questões relativas ao acervo, tanto de sua constituição, quanto de sua organização são pontos essenciais para a apreciação da atividade de leitura por parte de crianças e de jovens. É por isso que há a urgência da realização de ações planejadas e voltadas para a formação do jovem leitor.

Desse modo, condições de infraestrutura, variação e atualização do acervo, assim como sua forma de apresentação, fechado ou aberto, formação do responsável e desenvolvimento constante de projetos voltados para o incentivo e para o desenvolvimento de atividades de leitura constituem a base para a existência e o funcionamento de uma biblioteca escolar.

Ao final, podemos constatar que as bibliotecas escolares estão sendo deixadas de lado, estão desatualizadas, profissionais despreparados e até mesmo desmotivadas atuando na área, e que o local de funcionamento não é propício para tal fim.

As bibliotecas precisam urgentemente de uma atenção maior, pois as autoridades diretamente responsáveis, sendo os professores, gestores e demais profissionais da educação encontram-se de olhos fechados, não visualizam a necessidade de 
mudança. Dessa maneira, o que ainda ocorre é que muitos alunos saem do período de escolarização básica para a sociedade sem nenhum hábito de leitura - uma sociedade onde se torna cada vez fremente o letramento pela leitura.

Por fim, este trabalho se conjectura como uma pequena contribuição para a temática em questão, sendo importante realizar mais pesquisas como estas relacionadas a importância da leitura e das bibliotecas escolares para a formação do leitor, como também de práticas atrativas aos estudantes, ficando aqui a sugestão de uma revisão de literatura sobre os assuntos abordados.

\section{Referências}

Bamberger, R. (2005). Como incentivar o hábito de leitura. (7a ed.), Ática/UNESCO.

Becker, C. da R. F., \& Grosch, M. S. (2008). A formação do leitor através das bibliotecas: o letramento e a ciência da informação como pressupostos. Revista Brasileira de Biblioteconomia e Documentação, 1(1), 35-45.

Bicheri, A. L. A. de O., \& Júnior, O. F. A. (2013). Bibliotecário escolar: um mediador de leitura. Biblioteca Escolar em Revisão, 2 (1), 41-54.

El far, A. (2006). O livro e a leitura no Brasil. Jorge Zahar.

Ferreira, A. B. de H. (1986). Novo dicionário da língua portuguesa. (2a ed.), Nova Fronteira.

Figueiredo, T. D., Alves, C. C. G., Souza, C., Rodrigues, G. E. E., \& Pereira, C. A. (2021). A extensão universitária como agente de transformação social: um estudo de caso na Biblioteca Comunitária do bairro Saramenha de Cima - Ouro Preto / MG. Research, Society and Development, $10(16), 1-9$.

Francisco, A. C., Fernandes-sobrinho, M. (2020). Biblioteca e Educação Profissional e Tecnológica: lacunas e potencialidades frente aos aspectos formativos críticos. Research, Society and Development, 9(9), 1-26.

Freire, P. (1984-2003). A importância do ato de ler. Cortez.

Garcia, E. G. (1989). Biblioteca escolar: estrutura e funcionamento. Loyola.

Gil, A. C. (1999). Métodos e técnicas de pesquisa social. (5a ed.), Atlas.

Lakatos, E. M., \& Marconi, M. A. (2003). Fundamentos de metodologia cientifica. (5a ed.), Atlas.

Martins, M. H. (2003). O que é leitura. (17a ed.), Brasiliense.

Encyclopédia Britânnica do Brasil. (1997). Publicações Ltda.,1(2).

Manifesto da UNESCO sobre bibliotecas públicas. (1976). Revista Brasileira de Biblioteconomia e Documentação, 7(4/6), 158-163.

Minayo, M. C. de S. (Org.). (2003). Pesquisa Social: teoria, método e criatividade. Vozes.

Pimentel, G., Bernardes, L., \& Santana, M. (2007). Biblioteca escolar. Brasília: Universidade de Brasília.

Rodrigues, S. D., \& Martins, H. dos S. (2020). Avaliação da satisfação dos usuários de uma biblioteca universitária: análises e propostas com foco na aplicação de ferramentas da qualidade. Pesquisa, Sociedade e Desenvolvimento, 9(11), 1-23.

Silva, H. P. da. (2020). A fundação das bibliotecas públicas em alagoas: reclamações e reclamações da educadora maria maria (1953-1954). Research, Society and Development, 9(9), 1-17.

Silva, W. C. da. (1999). Miséria da biblioteca escolar. (2a ed.), Cortez.

Santos, J. M. O processo evolutivo das bibliotecas da antiguidade ao renascimento. (2012). Revista Brasileira de Biblioteconomia e Documentação, 8(2), 175189.

Válio, E. B. M. (1990). Biblioteca escolar: uma visão histórica. Trans-in-formação, 2(1), 15-24. 